\title{
Determinants of Cryptocurrency Market: An Analysis for Bitcoin, Ethereum and Ripple
}

\author{
Asena Deniz \\ Maya Plastik Incorp. \\ Istanbul, Turkey \\ Dilek Teker \\ Isık University \\ Faculty of Economics and Administrative Sciences \\ Istanbul, Turkey.
}

\begin{abstract}
One of the most important innovations brought by digitalization is crypto money known as virtual money. Cryptocurrencies, which have been discussed in recent years and especially a new portfolio for investors, are very popular. Bitcoin is the most well-known of these cryptographic systems, which do not depend on a central authority and have maximum reliability. The effects of various financial indicators on cryptoparas were examined in this study. The model includes a daily database in between April 3, 2018 to December 31, 2019. Initially stationarity is tested with unit root tests. Then cointegration and causality tests are employed. Impulse response is also implemented and analysed.
\end{abstract}

Key Words: Crypto currency market, financial markets, portfolio, unit root tests, cointegration, impulse response, causality

\section{JEL Classification: G10, G15, G17}

\section{Introduction}

This century, in which science and technology has developed rapidly, is beginning to cause new searches in the economic and financial fields. Due to these situations affecting both the financial structures and markets of countries, trends in different financial instruments are increasing. At the same time, these situations lead to a combination of finance and technology and an increase in digitalization. With digitalization, payment systems started to change first with the transfer and EFT transactions, a new one has been added to the digitalization steps and cryptocurrencies, i.e. virtual coins, have emerged. Cryptocurrencies, which have started to make their name with bitcoin today, are beginning to gain an important place in the financial World. Unlike traditional currencies, cryptocurrencies that are not subject to regulation by any institution, which are not subject to a central authority, can also be used as an investment tool like traditional currencies. Cryptocurrencies, a product of the virtual economy, have privacy due to blockchain technology. It is thought that cryptocurrencies can form the digital finance infrastructure of the future as a technological investment in the finance sector today, where technology has reached an indispensable point in people's life. Cryptocurrencies, which have recently become popular enough to compete with real money, are becoming the most valuable currencies in the world. Although around 3017 cryptocurrency are being traded; bitcoin has a share of around $67 \%$ in the cryptocurrency market. Therefore, majority of literature emloys models on bitcoin. The aim of this study is to figure out the interaction between cryptocurrency and macro variables. Bitcoin, Ethereum and Ripple is selected as represantative of crypto market. Gold and Brent oil prices are also modelled to highlight the interaction in between crpto currencies. In the study intially the crypto market is briefly explained which is followed by the literature analysis. Then econometric models are tested on the database.

\section{A General Perspective on Crypto Market}

Cryptocurrencies, also known as virtual money, have been described by the European Central Bank as “... a type of digital money that is issued (released) by its developers and generally controlled and controlled by them and accepted and used among members of a particular virtual community". (European Central Bank, 2012). It is called as cryptocurrencies due to trading in encrypted form according to a certain system. Market value is a measure used for traditional securities in determining the value of these known securities. The concept of market value is also important in the cryptocurrency market. Cryptocurrency market value is a mathematical method used to determine the value of a cryptocurrency. In cryptocurrencies, it is defined as the product of the circulating token supply 
multiplied by the current price. In contrast to traditional financial statements, cryptocurrencies do not publish financial statements and therefore do not carry out a ratio analysis.

Market value shows quickly and easily how much a cryptocurrency is worth. There are a total of 3070 cryptocurrencies on the market as of July 18, 2020, and the most famous of these coins is Bitcoin, which was the first cryptocurrency announced by Satoshi Nakamoto in 2008 with the article "Bitcoin: a Peer-to-Peer Electronic Cash System." The most widely used cryptocurrencies can be listed as " Bitcoin, Ethereum, Ripple, Litecoin, Tether, Cash, EOS, Dash, Cardano, Stellar, Monero, Eos, Bitcoin SV, Binance Coin, Bytecoin, Verge, Steem, ReddCoin, Funfair, Zcoin, BitCore".

\subsection{Bitcoin}

January 2008, Satoshi Nakamoto developed the first cryptocurrency as Bitcoin, the first production of which took place on January 3, 2009. Bitcoin is expressed as a virtual currency used in trading transactions that can be done without the need for an intermediary during digital transactions. Any transaction that can be done with physical money can be performed in purchases made using this system (Eğilmez, 2013). The amount of bitcoin in circulation in the period up to today is approximately 18,436 thousand. In the Bitcoin network, known as the Peer to peer system, computers do not connect to a server, each computer can connect to all computers that have their own address, such as a server, without the need for an agent. This situation provides the privacy of Bitcoin. The abbreviated version of the Bitcoin currency is known as "BTC". It can be used in Bitcoin, which can be divided up to 8 digits, with a minimum of 0.00000001 . "Satoshi" is the name given to the 8 th digit Bitcoin unit 100 million Satoshi means 1 BTC (Çarkacioğlu, 2016)

\subsection{Ethereum}

"Ethereum", which was first introduced by its founder Vitalik Buterin at the "North American Bitcoin Conference", has received an unexpectedly large amount of interest. Ethereum, which looks like an "altcoin" when viewed from the outside, is at its core a system with far more innovations compared to other altcoins. The Ethereum platform, whose main power source is ETH, allows the development of 'decentralized' software protocols on this operating system using its own proprietary spelling language. Ethereum, which ranks second in the virtual currency market after Bitcoin, is referred to as Bitcoin 2.0, or digital oil.

\subsection{Ripple}

Ripple, which means small wave of British origin, is a payment system in which large companies and banks can find an interlocutor, as a wire transfer network, and the feature is that large consistent payments can be made simultaneously, quickly swapping foreign currencies. At first, the project was aimed at making payments in the form of mutual debts and finding common acquaintances among people who knew each other. (Weber, 2016). Ripple's mission is to provide financial institutions with a common general ledger, to reconcile transactions and Exchange in low cost and real time, and to establish new and different systems to connect existing systems. In this context, Ripple started as the simplest element in the finance chain, especially for cross-border and national transactions, and has grown over time to reach a position that could potentially replace the "Single Euro Payment Area" and the "World Banking Financial Telecommunication Community". (Üzer, 2017).

\section{Literature Review}

One of the concepts that started to be used with the developments that emerged due to the impact of information technology is financial changes known as FinTech and the other is cryptocurrencies. The emergence and continuation of developments have a very different financial impact and in this context has created an opportunity to open up new service areas. Financial transformations aim to facilitate payment and transfer transactions, and with these innovations, the use of virtual and cryptocurrencies is increasing. The banknote issued by the state and accepted by law as a means of exchange is called fiat money. In more specific terms, the signatures under which the paper is printed cannot be imitated by others, and the banknotes used in the trading of goods and services with a sense of trust based on the central authority are referred to as fiat money. (Özdemir, 2012). As a new alternative currency, cryptocurrencies are defined as digital currencies because they allow encrypted transactions and allow additional virtual money supply to be created. To summarize, it is the general name given to fully digital, encrypted, virtual currencies that can be used in exchange transactions, completely independent from state authorities or intermediary institutions, traded over the internet. The high liquidity in cryptocurrencies is considered as an opportunity for investors and is therefore included in the classification of independent assets. (Sontakke ve Ghaisas, 2017). When we look at the literature, it is seen that many studies have been done on cryptocurrencies. These are the most empirical and theoretical studies on Bitcoin in the literature. Some studies on cryptocurrencies are summarized as follows.

Nakamoto (2008), the concept and idea of Blockchain first appeared in Satoshi Nakamoto's article published in 2008. The Nakamoto distributed database with bitcoin, which was introduced with the cryptopara idea, suggested 
the idea that there could be a solution to the problem of multiple spending on virtual currency. The study by Guo, Chow and Wigand (2011) aimed to design and implement a system in which virtual currency exchange rates are redetermined based on a redistribution strategy.

In this study, a new exchange rate algorithm was designed based on the redistribution strategy, it was observed that virtual exchange rates had a significant effect on the success or failure of virtual currency exchange.

Wijk (2013), Bitcoin prices and Nikkei 225, FTSE 100, Dow Jones, Dollar / Yen, Euro / Dollar and the prices of crude oil type "Western Texas Intermediate" (WTI Oil) were modelled to figure out the interaction in between these indicators. As a result of the analysis, it has been observed that Dow Jones index has a significant effect in the long and short term on the Bitcoin prices, while the Euro / Dollar and WTI Petroleum exchange rate have a short term and significant effect, whereas the Dollar / Yen and Nikkei 225 price movements have no significant effect. While Halaburda and Gandal (2014) could not exactly identify Bitcoin as a commodity or currency, Baur and Lucey (2010) have stated that Bitcoin can be an important tool for improving the performance of portfolios.

In their study, Brière, Oosterlinck and Szafarz (2015) concluded that Bitcoin provides higher returns despite increasing variance for the portfolio, positively impacting the risk-return balance of portfolios and could be an important tool in portfolio diversification. They have argued that financial analysts should put more emphasis on Bitcoin. Dyhrberg's (2016) study used the asymmetric GARCH method. According to Dyhrberg, Bitcoin acts like a hedge instrument in a similar way to gold. Therefore, in a portfolio with stocks and dollars, Bitcoin should be treated like a hedge instrument. According to Dwyer (2015), Bitcoin's returns are also above those two asset classes, although it is observed that the variance of bitcoin's returns lies on both gold and foreign currencies pairs.

The study "cryptocurrency and blockchain bring to the new world" by Çetiner (2018) stated that this currency will be one of the important financial instruments in the future new world order. In the study, Bitcoin is considered to provide an infrastructure for the work to be done by public, private and academicians in order to build and develop a blockchain-based infrastructure in the future.

\section{Data and Methodology}

In this study, the interaction between Bitcoin Ethereum, Ripple, gold and brent oil was examined using time series models. The Daily data is used in between April 3, 2018 to December 31, 2019. The natural logaritms are used in the models. Initially unit root tests are implemented. Then cointegration tests and causality tests are employed. Impulse response is also analysed.

\subsection{Unit Root Test Results}

The degree of stationarity of the series is very important in time series analysis. As Elder and Kennedy (2001) explains, wrong results may be developed if the stationarity degrees of the data is not checked. In the Dickey-Fuller test, the time series cannot be expressed by First-Order autoregressive process if autocorelation is present in the error term. In this case, "Augmented Dickey-Fuller" test was developed to test the unit root existence. (Göktaş, 2005). In this study, the stationarity of the series is tested with ADF test statistics. In the stationary test for Bitcoin, Ethereum, Ripple, gold and brent oil; ADF test value contains unit root since it is logarithmically smaller than McKinnon critical values at $1 \%, 5 \%$ and $10 \%$ significance levels. In order to eliminate the unit root, the first degree difference of the series was taken and the stationary test was performed again. If the H0 hypothesis is rejected, it is interpreted that the series is stationary and the resulting results are shown in the following images.

Table 1: ADF Unit Root Test Results

\begin{tabular}{|c|c|c|c|c|c|c|}
\hline \multirow[t]{2}{*}{ Variable } & \multirow[t]{2}{*}{ Symbol } & \multirow{2}{*}{$\begin{array}{l}\text { ADF Test } \\
\text { Statistics } \\
\end{array}$} & \multicolumn{3}{|c|}{ Mac-Kinnon Critical Values } & \multirow[t]{2}{*}{ Probability* } \\
\hline & & & $1 \%$ & $5 \%$ & $10 \%$ & \\
\hline Gold & & $-28,9458$ & $-3,443254$ & $-2,867124$ & $-2,569806$ & 0,0000 \\
\hline Brent Oil & & $-24,73157$ & $-3,443254$ & $-2,867124$ & $-2,569806$ & 0,0000 \\
\hline Bitcoin & BTC & $-22,93680$ & $-3,443254$ & $-2,867124$ & $-2,569806$ & 0,0000 \\
\hline Ethereum & ETH & $-23,22374$ & $-3,443254$ & $-2,867124$ & $-2,569806$ & 0,0000 \\
\hline Ripple & $\mathrm{XRP}$ & $-21,46952$ & $-3,443254$ & $-2,867124$ & $-2,569806$ & 0,0000 \\
\hline
\end{tabular}

Test statistics values in Table 1 are smaller than critical values, probability value is less than 0.05 and absolute value of $\mathrm{ADF}$ test statistics is greater than $1 \%, 5 \%$ and $10 \%$ of Mac Kinnon critical values Gold, Brent Petrol, Bitcoin, Ethereum Shows that Ripple variables are equally stable.

\subsection{VAR Model, the Lang Length Criteria and Johansen Cointegration Test}


In order to talk about the existence of a long-term relationship between the series, it is necessary to examine whether they are cointegrated. For this, the lang lengths criteria of the variables used in the model were found with an unconstrained VAR model. The lang lengths criteria determined according to the result of the connection of each cryptocurrency with gold and brent oil are as follows.

Table 2. The Lang Length Criteria Results for Bitcoin

\begin{tabular}{|l|l|l|l|l|l|}
\hline $\begin{array}{l}\text { The Lang } \\
\text { Length } \\
\text { Criteria }\end{array}$ & LR & FPE & AIC & SIC & HQ \\
\hline 0 & NA & $2,41 \mathrm{E}-06$ & $-4,423215$ & $-4,397694$ & $-4,413195$ \\
\hline 1 & 5218,7 & $5,92 \mathrm{E}-11^{*}$ & $-15,03719$ & $-14,93510^{*}$ & $-14,99711$ \\
\hline 2 & $43,78146^{*}$ & $5,61 \mathrm{E}-11$ & $-15,09065^{*}$ & $-14,82422$ & $-15,020551^{*}$ \\
\hline 3 & 12,20981 & $5,67 \mathrm{E}-11$ & $-15,07944$ & $-14,82422$ & $-14,97924$ \\
\hline 4 & 11,61651 & $5,74 \mathrm{E}-11$ & $-15,06715$ & $-14,73537$ & $-14,9369$ \\
\hline 5 & 10,03706 & $5,83 \mathrm{E}-11$ & $-15,05171$ & $-14,64337$ & $-14,8914$ \\
\hline 6 & 15,44543 & $5,85 \mathrm{E}-11$ & $-15,04779$ & $-14,56289$ & $-14,85742$ \\
\hline
\end{tabular}

Table 3. The Lang Length Criteria Results for Ethereum

\begin{tabular}{|l|l|l|l|l|l|}
\hline $\begin{array}{l}\text { The Lang } \\
\text { Length } \\
\text { Criteria }\end{array}$ & LR & FPE & AIC & SIC & HQ \\
\hline 0 & NA & $2,58 \mathrm{E}-06$ & $-4,354466$ & $-4,328944$ & $-4,344446$ \\
\hline 1 & 4992,992 & $1,00 \mathrm{E}-10$ & $-14,50781$ & $-14,40572^{*}$ & $-14,46773$ \\
\hline 2 & 42,56714 & $9,55 \mathrm{E}-11^{*}$ & $-14,55878^{*}$ & $-14,38013$ & $-14,48864^{*}$ \\
\hline 3 & 8,909063 & $9,72 \mathrm{E}-11$ & $-14,54075$ & $-14,28553$ & $-14,44055$ \\
\hline 4 & 9,463082 & $9,88 \mathrm{E}-11$ & $-14,52398$ & $-14,1922$ & $-14,39373$ \\
\hline 5 & 18,20443 & $9,87 \mathrm{E}-11$ & $-14,52563$ & $-14,11729$ & $-14,36532$ \\
\hline 6 & $20,2898^{*}$ & $9,81 \mathrm{E}-11$ & $-14,53136$ & $-14,04645$ & $-14,34099$ \\
\hline
\end{tabular}

Table 4. The Lang Length Criteria Results for Ripple

\begin{tabular}{|l|l|l|l|l|l|}
\hline $\begin{array}{l}\text { The Lang } \\
\text { Length } \\
\text { Criteria }\end{array}$ & LR & FPE & AIC & SIC & HQ \\
\hline 0 & NA & $1,38 \mathrm{E}-06$ & $-4,983066$ & $-4,957544$ & $-4,973046$ \\
\hline 1 & 4721,329 & $9,33 \mathrm{E}-11$ & $-14,58199$ & $-14,47991^{*}$ & $-14,54192$ \\
\hline 2 & 42,97655 & $8,86 \mathrm{E}-11^{*}$ & $-14,63381^{*}$ & $-14,45515$ & $-14,56367 *$ \\
\hline 3 & 8,554156 & $9,02 \mathrm{E}-11$ & $-14,61504$ & $-14,35983$ & $-14,51484$ \\
\hline 4 & 5,354639 & $9,25 \mathrm{E}-11$ & $-14,58973$ & $-14,25195$ & $-14,45947$ \\
\hline 5 & 12,80383 & $9,34 \mathrm{E}-11$ & $-14,58008$ & $-14,17174$ & $-14,41976$ \\
\hline 6 & $19,4194^{*}$ & $9,30 \mathrm{E}-11$ & $-14,58453$ & $-14,09962$ & $-14,39415$ \\
\hline
\end{tabular}

According to the outputs presented above in tables 2,3, and 4; the lag length for Bitcon,Ethereum and Ripple was determined as 2 . The Johansen co-integration test and VAR test were performed. In order to interpret the statistical data of long-term relationships between variables, the series must be integrated in the same degree. For instance the stationarity in the first difference enabled us to run cointegration test. The outputs are illustrated in Table 5. 
Table 5. Johansen Cointegration Test Results

\begin{tabular}{|c|c|c|c|c|c|c|}
\hline \multirow{2}{*}{$\begin{array}{l}\text { Cointegration } \\
\text { Degree- } \\
\text { Bitcoin }\end{array}$} & \multicolumn{3}{|c|}{ Trace Statistic } & \multicolumn{3}{|c|}{ Max Eigenvalue Statistic } \\
\hline & $\begin{array}{l}\text { Calculate } \\
\text { d Value }\end{array}$ & $\begin{array}{l}\text { Table Value } \\
\% 5\end{array}$ & Probability & $\begin{array}{l}\text { Calculated } \\
\text { Value }\end{array}$ & $\begin{array}{l}\text { Table Value } \\
\% 5\end{array}$ & Probability \\
\hline $\mathrm{r} \leq=0$ & 24,62282 & 35,19275 & 0,4233 & 17,08098 & 35,19275 & 0,2282 \\
\hline $\mathrm{r} \leq=1$ & 7,541837 & 20,26184 & 0,8600 & 5,10447 & 20,26184 & 0,8791 \\
\hline $\mathrm{r} \leq=2$ & 2,437368 & 9,164546 & 0,6900 & 2,43768 & 9,164546 & 0,6900 \\
\hline \multirow{2}{*}{$\begin{array}{l}\text { Cointegration } \\
\text { Degree- } \\
\text { Ethereum }\end{array}$} & \multicolumn{3}{|c|}{ Trace Statistic } & \multicolumn{3}{|c|}{ "Max Eigenvalue Statistic } \\
\hline & $\begin{array}{l}\text { Calculate } \\
\text { d Value }\end{array}$ & $\begin{array}{l}\text { Table } \\
\text { Value \%5 }\end{array}$ & $\begin{array}{l}\text { Calculated } \\
\text { Value }\end{array}$ & $\begin{array}{l}\text { Table } \\
\text { Value } \% 5\end{array}$ & $\begin{array}{l}\text { Calculated } \\
\text { Value }\end{array}$ & $\begin{array}{l}\text { Table } \\
\text { Value \%5 }\end{array}$ \\
\hline $\mathrm{r} \leq=0$ & 19,47046 & 39,19275 & 0,7592 & 11,99583 & 22,29962 & 0,6553 \\
\hline $\mathrm{r} \leq=1$ & 7,47483 & 20,26184 & 0,8649 & 5,180304 & 15,8921 & 0,8722 \\
\hline $\mathrm{r} \leq=2$ & 2,294526 & 9,164546 & 0,7187 & 2,294526 & 9,164546 & 0,7187 \\
\hline \multirow{2}{*}{$\begin{array}{l}\text { Cointegration } \\
\text { Degree- } \\
\text { Ripple }\end{array}$} & \multicolumn{3}{|c|}{ Trace Statistic } & \multicolumn{3}{|c|}{ Max Eigenvalue Statistic } \\
\hline & $\begin{array}{l}\text { Calculated } \\
\text { Value }\end{array}$ & $\begin{array}{l}\text { Table } \\
\text { Value \%5 }\end{array}$ & $\begin{array}{l}\text { Calculated } \\
\text { Value }\end{array}$ & $\begin{array}{l}\text { Table } \\
\text { Value \%5 }\end{array}$ & $\begin{array}{l}\text { Calculated } \\
\text { Value }\end{array}$ & $\begin{array}{l}\text { Table } \\
\text { Value } \\
\% 5\end{array}$ \\
\hline $\mathbf{r} \leq=\mathbf{0}$ & 17,25555 & 24,27596 & 0,2952 & 12,30383 & 17,7973 & 0,2761 \\
\hline$r \leq=1$ & 4,951718 & 12,3209 & 0,5743 & 4,870076 & 11,2248 & 0,4958 \\
\hline $\mathbf{r} \leq=\mathbf{2}$ & 0,081642 & 4,129906 & 0,8145 & 0,081642 & 4,129906 & 0,8145 \\
\hline
\end{tabular}

In the long term, the Johansen Cointegration test was used to determine whether there was a significant relationship between these variables. According to the cointegration analysis results, our probability value is greater than 0.05 . According to our hypothesis, $\mathrm{H}_{0}$ cannot be rejected, so there is no cointegration between these values.

\subsection{Granger Causality Test Results}

Causality test should also performed to determine the direction of the relationship between the variables (Bağdigen and Beșer, 2009). Causality is the statistical sense that the future estimated values of another related time series variable or itself or a time series variable are obtained by influencing the past period values (Işığıçok, 1994). According to Granger's recognition in 1969 , if the $\mathrm{Y}_{\mathrm{t}}$ variable can be estimated more accurately by using the historical values of the $X_{t}$ variable than when these values are not used, the $X_{t}$ is called the Granger cause of $Y_{t}$. To put it more simple, the causality dimension is measured by analyzing whether the lagged values of one variable can be used to explain another variable. For example, if the delayed values of variable (x) have a significant effect on variable (y), it is said that $(x, y)$ is the cause of Granger.

To determine the direction of causality between variables, Granger causality test results were obtained (Table 6). According to the results obtained with Granger Causality test findings; depending on the probability value being less than 5\%, a unilateral causality relationship has emerged from Bitcoin to Gold. According to the findings, Bitcoin is the Granger cause of Gold. According to Ethereum results, a one-sided causality relationship has emerged from Brent oil to Gold. Brent oil is Gold's Granger cause. Ethereum has no causal relationship with neither Gold nor Brent oil. According to the causality analysis for Ripple, a one-sided causality relationship has emerged from de Brent oil to Gold. Brent oil is Gold's Granger cause. Ripple has no causal relationship with both Gold and Brent oil. The results of the test are included in Table 6.

Tablo 6. Granger Causality Tests

\begin{tabular}{|l|l|l|}
\hline & $\begin{array}{l}\text { Probability } \\
\text { Value }\end{array}$ & Result \\
\hline Bitcoin $\rightarrow$ Gold & 0,0133 & There is a causality relationship from Bitcoin to Gold. \\
\hline Bitcoin $\rightarrow$ Brent Oil & 0,1585 & $\begin{array}{l}\text { There is no causality relationship from Bitcoin to Brent } \\
\text { Oil. }\end{array}$ \\
\hline Gold $\rightarrow$ Bitcoin & 0,6862 & There is no causality relationship from Gold to Bitcoin. \\
\hline Gold $\rightarrow$ Brent Oil & 0,0702 & There is no causality relationship from Gold to Brent oil. \\
\hline Brent Oil $\rightarrow$ Gold & 0,6850 & There is no causality relationship from Brent oil to Gold. \\
\hline Brent Oil $\rightarrow$ Bitcoin & 0,8004 & There is no causality relationship from Brent oil to \\
\hline
\end{tabular}




\begin{tabular}{|c|c|c|}
\hline & & Bitcoin. \\
\hline Ethereum $\rightarrow$ Gold & 0,3978 & There is no causality relation from Ethereum to Gold. \\
\hline Ethereum $\rightarrow$ Brent Oil & 0,4840 & $\begin{array}{l}\text { There is no causality relationship from Ethereum to Brent } \\
\text { Oil. }\end{array}$ \\
\hline Gold $\rightarrow$ Ethereum & 0,9399 & There is no causality relation from Gold to Ethereum. \\
\hline Gold $\rightarrow$ Brent Oil & 0,0709 & There is no causality relationship from Gold to Brent oil. \\
\hline Brent Oil $\rightarrow$ Ethereum & 0,8563 & There is no causality relation from Brent Oil to Ethereum. \\
\hline Brent Oil $\rightarrow$ Gold & 0,0253 & There is a causality relationship from Brent oil to Gold. \\
\hline Ripple $\rightarrow$ Gold & 0,7278 & There is no causal relationship from Ripple to Gold. \\
\hline Ripple $\rightarrow$ Brent Oil & 0,7276 & $\begin{array}{l}\text { There is no causality relationship from Ripple to Brent } \\
\text { oil. }\end{array}$ \\
\hline Gold $\rightarrow$ Ripple & 0,5831 & There is no causality relationship from Gold to Ripple. \\
\hline Gold $\rightarrow$ Brent Oil & 0,0797 & There is no causality relationship from gold to Brent oil. \\
\hline Brent Oil - & 0,8976 & $\begin{array}{l}\text { There is no causality relationship from Brent oil to } \\
\text { Ripple. }\end{array}$ \\
\hline Brent Oil $\rightarrow$ Gold & 0,0235 & There is a causality relationship from Brent oil to Gold. \\
\hline Ethereum $\rightarrow$ Gold & 0,3978 & There is no causality relation from Ethereum to Gold. \\
\hline Ethereum $\rightarrow$ Brent Oil & 0,4840 & $\begin{array}{l}\text { There is no causality relationship from Ethereum to Brent } \\
\text { Oil. }\end{array}$ \\
\hline Gold $\rightarrow$ Ethereum & 0,9399 & There is no causality relation from Gold to Ethereum. \\
\hline Gold $\rightarrow$ Brent Oil & 0,0709 & There is no causality relationship from Gold to Brent oil. \\
\hline Brent Oil $\rightarrow$ Ethereum & 0,8563 & There is no causality relation from Brent Oil to Ethereum. \\
\hline Brent Oil $\rightarrow$ Gold & 0,0253 & There is a causality relationship from Brent oil to Gold. \\
\hline Ripple $\rightarrow$ Gold & 0,7278 & There is no causal relationship from Ripple to Gold. \\
\hline Ripple $\rightarrow$ Brent Oil & 0,7276 & $\begin{array}{l}\text { There is no causality relationship from Ripple to Brent } \\
\text { oil. }\end{array}$ \\
\hline Gold $\rightarrow$ Ripple & 0,5831 & There is no causality relationship from Gold to Ripple. \\
\hline Gold $\rightarrow$ Brent Oil & 0,0797 & There is no causality relationship from gold to Brent oil. \\
\hline Brent Oil $\rightarrow$ Ripple & 0,8976 & $\begin{array}{l}\text { There is no causality relationship from Brent oil to } \\
\text { Ripple. }\end{array}$ \\
\hline Brent Oil $\rightarrow$ Gold & 0,0235 & There is a causality relationship from Brent oil to Gold. \\
\hline
\end{tabular}

Since the direct interpretation of the VAR model results will not make much sense, they have also been interpreted with effect-response and variance decomposition analyses.

\subsection{Impact-Response Analyses Results}

Impulse-response functions reflect the impact of a standard error shock in one of the random error terms on the present and future values of the internal variables. With variance decomposition, the most effective variable on a macroeconomic size can be determined. Whether this variable can be used as a policy tool is determined whether the effect is proved with the effect-response functions. (Özgen ve Güloğlu, 2004).

Graph 1: Bitcoin Impact Response Test Results

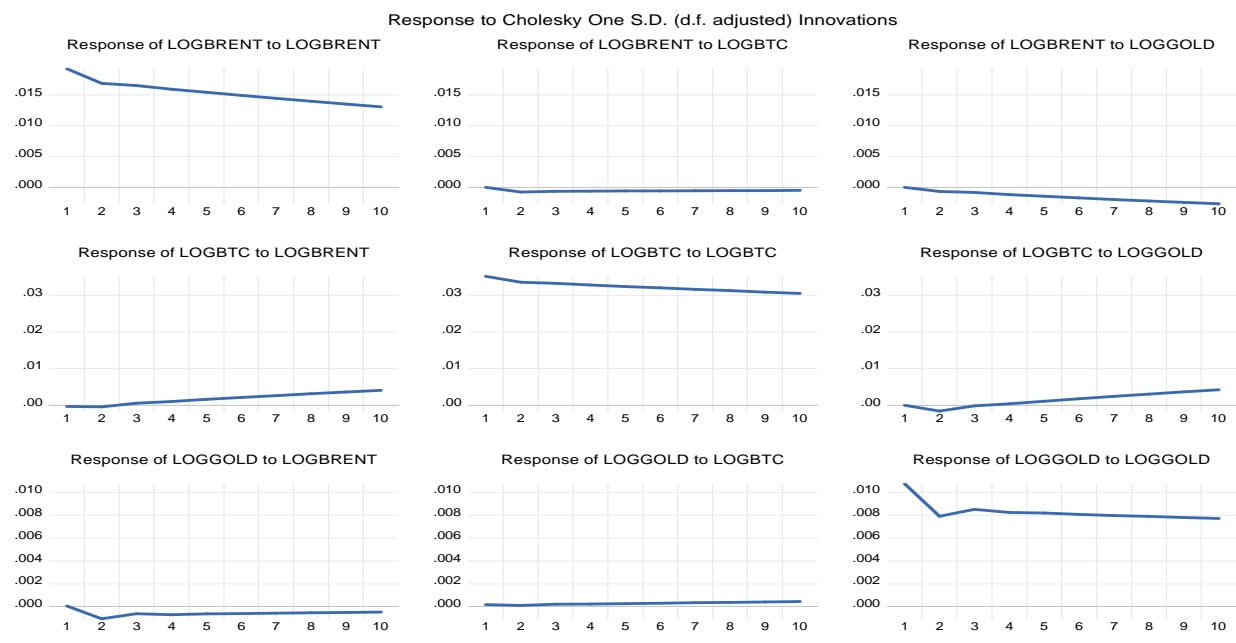


Looking at the impact reaction charts between Bitcoin, Commodity and Gold, it was seen that shocks given to Bitcoin did not have a significant effect on Gold and Commodity. Likewise, a shock to commodity did not seem to have a significant effect on Gold andBbitcoin. And finally, a shock to Gold has been found to have no significant effect on Commodities and Bitcoin. The given shocks lost their effect in an average of 2 days.

\section{Graph 2: Ethereum Impact Response Test Results}

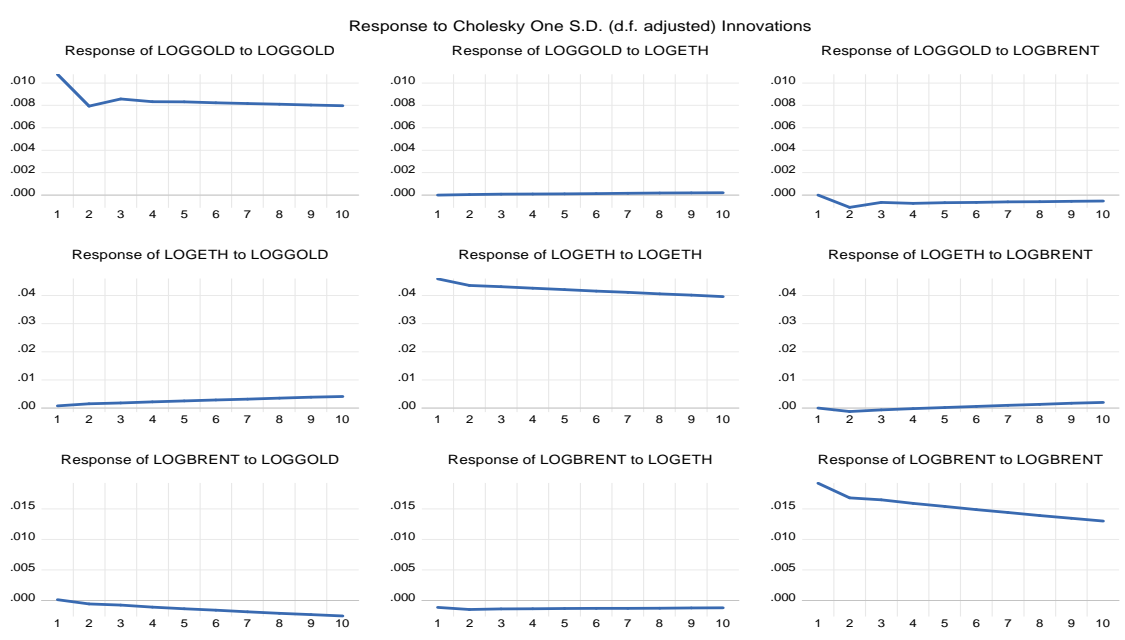

Looking at the impact reaction graphs between Ethereum, Commodity and Gold, it was seen that the shocks given to Ethereum did not have a significant effect on gold and commodity. Likewise, a shock to commodity has not been found to have a significant effect on gold and ethereum. And finally, a shock to Gold has been found to have no significant effect on Commodities and Ethereum. The given shocks lost their effect in an average of 2 days.

Graph 3: Ripple Impact Response Test Results

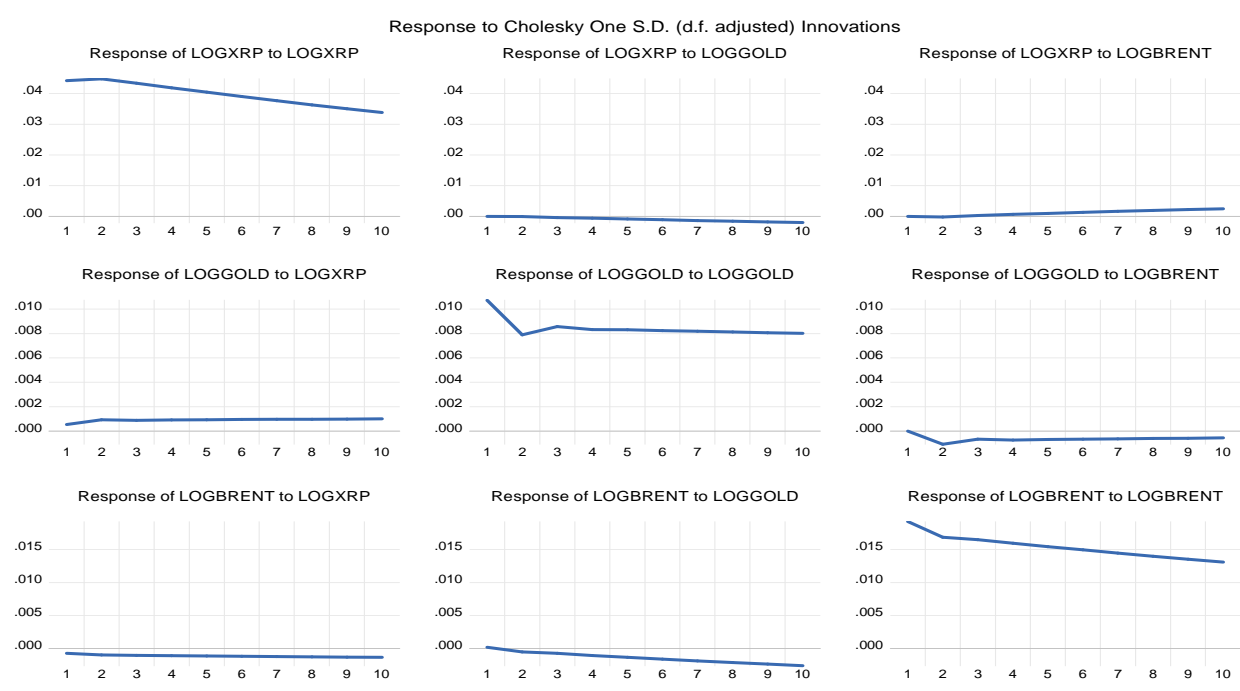

When Ripple looked at the impact response charts between commodity and gold, it was seen that shocks to Ripple did not have a meaningful effect on the gold commodity. Likewise, a shock to commodities was found to have no meaningful effect on gold and Ripple. And finally, a shock to Gold has not had a meaningful effect on commodities and ripple. The given shocks lost their effect in an average of 2 days.

\subsection{Variance Decomposition}

The study that distinguishes the change in one of the intrinsic variables as separate shocks affecting all the intrinsic variables is called variance decomposition. It gives information about the dynamic structure of the system and its 
purpose is to reveal the effect of each random shock on the error variance of the prediction for future periods. It is also important to interpret the results obtained from the variance decomposition because the order of the variables affects the results. Table 7, 8 and 9 are the results of variance decomposition of our variables.

Table 7. Bitcoin Variance Decomposition

\begin{tabular}{|l|l|l|l|l|}
\hline PERIOD & S.E. & $\begin{array}{l}\text { BRENT } \\
\text { OIL }\end{array}$ & BITCOIN & GOLD \\
\hline 1 & 0,035151 & 0,009396 & 99,99060 & 0,000000 \\
\hline 2 & 0,048630 & 0,012395 & 99,87556 & 0,112045 \\
\hline 3 & 0,058904 & 0,016734 & 99,90607 & 0,077198 \\
\hline 4 & 0,067426 & 0,035380 & 99,90266 & 0,061964 \\
\hline 5 & 0,074830 & 0,074578 & 99,85269 & 0,072728 \\
\hline 6 & 0,081431 & 0,131328 & 99,75965 & 0,109027 \\
\hline 7 & 0,087425 & 0,205285 & 99,62333 & 0,171382 \\
\hline 8 & 0,092939 & 0,295101 & 99,44645 & 0,258453 \\
\hline 9 & 0,098062 & 0,399662 & 99,23134 & 0,368996 \\
\hline 10 & 0,102861 & 0,517783 & 98,98070 & 0,501518 \\
\hline
\end{tabular}

According to Table 7, while nearly $100 \%$ of the shock coming to Bitcoin can be explained by itself in the first period, $99 \%$ of the shock in the 10th period is explained by gold and emitate.

Table 8. Ethereum Variance Decomposition

\begin{tabular}{|l|l|l|l|l|}
\hline Period & S.E. & GOLD & ETHEREUM & BRENT OIL \\
\hline 1 & 0,045938 & 0,030502 & 99,96950 & 0,000000 \\
\hline 2 & 0,063369 & 0,074772 & 99,88625 & 0,038976 \\
\hline 3 & 0,076705 & 0,108930 & 99,85812 & 0,032947 \\
\hline 4 & 0,087791 & 0,147976 & 99,82639 & 0,025630 \\
\hline 5 & 0,097410 & 0,190692 & 99,78797 & 0,021336 \\
\hline 6 & 0,105970 & 0,237492 & 99,74107 & 0,021433 \\
\hline 7 & 0,113717 & 0,288139 & 99,68555 & 0,026307 \\
\hline 8 & 0,120814 & 0,342449 & 99,62157 & 0,035985 \\
\hline 9 & 0,127374 & 0,400195 & 99,54947 & 0,050340 \\
\hline 10 & 0,133483 & 0,461149 & 99,46968 & 0,069170 \\
\hline & & & & \\
\hline
\end{tabular}

According to Table 8, while almost $100 \%$ of the shock coming to Ethereum can be explained from the first period, $99.4 \%$ of the shock is explained in gold and $0.06 \%$ from the commodity in the 10th period. 
Table 9. Ripple Variance Decomposition

\begin{tabular}{|l|l|l|l|l|}
\hline Period & S.E. & RIPPLE & GOLD & BRENT OIL \\
\hline 1 & 0,044239 & 100,0000 & 0,000000 & 0,000000 \\
\hline 2 & 0,063000 & 99,99927 & $8,65 \mathrm{E}-05$ & 0,000647 \\
\hline 3 & 0,076510 & 99,99632 & 0,002114 & 0,001568 \\
\hline 4 & 0,087239 & 99,98711 & 0,006211 & 0,006676 \\
\hline 5 & 0,096168 & 99,97080 & 0,012786 & 0,016416 \\
\hline 6 & 0,103802 & 99,94725 & 0,021955 & 0,030795 \\
\hline 7 & 0,110445 & 99,91647 & 0,033895 & 0,049639 \\
\hline 8 & 0,116298 & 99,87851 & 0,048751 & 0,072738 \\
\hline 9 & 0,121502 & 99,83348 & 0,066668 & 0,099855 \\
\hline 10 & 0,126163 & 99,78147 & 0,087783 & 0,130749 \\
\hline
\end{tabular}

According to Table 9, $100 \%$ of a shock coming to Ripple is explained from the first period, while $10.8 \%$ of the shock above Ripple is explained by gold and $0.01 \%$ from brent oil.

\section{Conclusion}

In recent times, alternative payment methods have changed by switching from traditional trade to more ecommerce. This new concept suggests that money can be virtual and transactions can be made faster with virtual money. The foundations for the emergence of a new digital era based on Blockhain technology and realized entirely with digital currencies are also being established. As a different investment alternative, cryptocurrencies attract the attention of investors. Investors think of cryptocurrencies as an alternative investment tool to their savings. They can evaluate their savings both in money markets, capital markets and crypto money markets. However, cryptocurrencies do not make sense for investors if they are invested by evaluating alone. Therefore, they need to consider both the price movements of cryptocurrencies and the relationship between someone and the interaction between cryptocurrencies and real currencies. In this study, the cryptocurrencies that emerged as a new investment instrument in the financial markets. Not only the Bitcoin as the most popular cryptocurrency but also Etherium and Ripple is selected due to their high market shares. The studys employs a series of econometric tests to investigate how these virtual currencies have effected from gold and brent oil price movements. Due to the results of cointegration and granger causality analysis, it was found that only Bitcoin is the Granger cause of Gold therefore has a short term impact on gold prices. There is no Granger causality between Ethereum, Ripple, gold and brent oil.

\section{References}

Brière, M., Oosterlinck, K., and Szafarz, A. (2015).. Virtual currency, tangible return: Portfolio diversification with Bitcoin. Journal of Asset Management, 365-373.

Çakracioğlu, A. (2016). Crypto Money Bitcoin. Capital Markets Board Research Report http://www.spk.gov.tr/SiteApps/Yayin/YayinGoster/1130. Date: 27.07.2020.

Çetiner, M., (2018).. Bitcoin (Cryptocurrency) and the Blockchain Brings to the New World. Istanbul Journal of Social Sciences. Q.20.

Dyhrberg, A. (2016).. Hedging capabilities of bitcoin. Is it the virtual gold? Finance Research Letters.

Eğilmez, M. (2013). Bitcoin. http://www.mahfiegilmez.com/2013/11/bitcoin.html (Access Date: 22.07.2020).

European Central Bank, (2012). Virtual Currency Schemes, https://www.ecb.europa.eu/pub/pdf/other/virtualcurrencyschemes201210en.pdf.

(Access Date: 22.07.2020)

Göktaş, Ö. (2005). Theoretical and Applied Time Series Analysis. Beşir Publications. Istanbul.

Guo J., Chow A. Wigand R. T. (2011). Virtual wealth protection through virtual money Exchange, Electronic Commerce Research and Application, 10. s.313-330.

Halaburda, H., and Gandal, N. (2014). Competition in the Cryptocurrency Market. Received from https://www.econstor.eu/bitstream/10419/103022/1/791932281.pdf .

Işıkçok, E. (1994). Causality Analysis in Time Series. Bursa: Uludağ University Printing House.

Nakamoto, S. (2008). Bitcoin: A Peer-to-Peer Electronic Cash System. Bitcoin.org. Received from http://web.archive.org/web/201604170 00233/https://Bitcoin.org/Bitcoin.pdf Access Date: 22.07. 2020 .

Özdemir B. K. (2012). Money Theory, Development of the Payment System". Anatolian University. 187 p.

Özgen, F.B. and Güloğlu, B. (2004). VAR Technical Analysis of the Economic Impact of Domestic Debt in Turkey. METU Studies in Development. 31: 93-114. 
Sontakke, K. A. and G. Aishwarya. (2017). Crypto Currencies: A Developing Asset Class, Internatioanal Journal of Business Insight and Transformation, 10(2), pp. 10-17.

Üzer, B. (2017). Virtual Currencies. Specialization Proficiency Thesis. Payment Systems Directorate General of Central Bank of the Republic of Turkey in Ankara, September 2017

Weber, B. (2016). Competing for Legitimacy: A Typology for Virtual Currencies. 2nd Workshop on P2P Financial Systems 2016, London. 